\title{
Estimating earth loads on buried pipes under axial loading condition: insights from 3D discrete element analysis
}

\author{
Masood Meidani, Mohamed A. Meguid ${ }^{*}$ (i) and Luc E. Chouinard
}

*Correspondence:
mohamed.meguid@mcgill.ca
Department of Civil
Engineering and Applied
Mechanics, McGill University,
817 Sherbrooke St. W.,
Montreal, QC H3A 0C3,
Canada

*Correspondence: Engineering and Applied Mechanics, McGill University, Canada

\begin{abstract}
The response of a buried pipe subjected to relative axial ground movement is investigated in this study using three-dimensional discrete element analysis. A discrete element model that is able to simulate the particulate nature of the granular material and the continuous nature of the pipe was developed. The micro-parameters of the model were calibrated using triaxial tests. The developed pipe-soil model was validated using experimental data and then used to calculate the pipe response to axial loading under varying soil conditions. A comparison was also made between the calculated response and the available closed-form solutions. Results indicated that, for pipes installed in dense sand, existing solutions may not properly account for the dilative behavior of the soil and hence underestimate the axial soil resistance. A parametric study was performed using the validated model to evaluate the factors controlling the axial soil resistance under these loading conditions. The contributing parameters are found to be the pipe diameter, burial depth, and soil properties. Results of the parametric study were used to develop an expression to estimate the earth pressure coefficient that reflects the dilative nature of the soil. An example is provided to illustrate the use of the proposed expression in estimating the maximum soil resistance to pullout loading.
\end{abstract}

Keywords: Soil-pipe interaction, Pullout capacity, Steel pipelines, Axial soil resistance, Discrete element analysis

\section{Introduction}

Buried pipelines are considered to be among the safest, most efficient and economical ways of transporting and delivering natural resources. According to the Canadian Energy Pipeline Association (CEPA) [6], pipelines network transport more than $90 \%$ of onshore oil and gas from producing fields to markets throughout North America. Therefore, they are considered strategic infrastructure and often referred to as "lifeline" systems. Failures of these systems can have a significant impact on the environment, and the economy as well as public safety.

Damage to buried pipelines may occur due to corrosion, external loading, construction defects and ground movement. Permanent ground deformations (PGD) resulting from seismic activities may lead to lateral spreading, liquefaction, slope movement, and landslides. Although the risk of PGD is usually limited to small regions of the pipeline network, the damage potential could be very high as a result of the induced differential 
movements [26]. A report of the European Gas Pipeline Incident Data Group [14] has indicated that ground movement represents the fourth major cause of gas pipeline failure with close to half of the reported PGD cases resulting in pipe rupture.

Ground movement induced by slope instability can be classified as shallow or deepseated depending on the geometry and geotechnical conditions of the slope [7]. The interaction between a buried pipe and a moving slope is a function of the pipe orientation with respect to the slope. When the pipe axis is normal to the direction of soil movement, the pipe is subjected to lateral forces resulting in bending stresses and shear forces in the pipe wall. When the pipe is parallel to the slope, tensile or compressive stresses are induced in the pipe due to the slope movement. This study focuses on estimating the axial load on a pipe subjected to relative axial soil movement.

The interaction between a buried pipe and the surrounding soil is conceptually similar to the shaft resistance of displacement piles. The ultimate axial soil resistance of a buried pipe in granular material is obtained by considering the interaction at the interface between the pipe and the surrounding soil. A commonly used approach to determine the axial soil load $F_{A}$ for pipes buried in cohesionless sand is that suggested by the American Society of Civil Engineering [4]:

$$
F_{A}=0.5 \times \gamma^{\prime} \times H \times(\pi D L) \times\left(1+K_{0}\right) \times \tan (\delta)
$$

where, $\gamma^{\prime}$ is the soil effective unit weight, $H$ is the depth to pipe centerline, $D$ is the pipe outer diameter, $L$ is the pipe length, $K_{0}$ is the coefficient of earth pressure at-rest and $\delta$ is the interface friction angle between the soil and the pipe. Equation (1) has been also recommended by the American Lifeline Alliance [3] and Honegger and Nyman [18] to calculate axial soil loads on buried pipe in granular material. The term $0.5 \pi D \gamma^{\prime} H\left(1+K_{0}\right)$ in Eq. (1) represents the average effective normal stress acting on the outer perimeter of the pipe, which corresponds to the "at-rest" condition. When lateral strains develop in the soil due to the relative movement between the soil and the pipe, normal stresses on the pipe increase compared to the at-rest condition and consequently Eq. (1) would underestimate the axial soil resistance. Several researchers, e.g. [21, 24, 28, 38] reported significant discrepancies between the predicted values calculated using Eq. (1) and the experimentally measured axial soil resistance. It was also found that the peak axial pullout force for pipelines in dry dense sand is several times higher than those obtained using the closed-form solutions. The increase in axial pullout force is attributed to the increase in normal stresses due to the dilatant behaviour of the sand under interface shear deformations. A parameter $K$ was proposed instead of $K_{0}$ in Eq. (1) based on experimental data to account for the increase in the radial soil stresses acting on the pipe.

In this study, three-dimensional (3D) discrete element models are developed and used to simulate large-scale pullout experiments on pipes in granular material. The model is first calibrated using experimental data and then used to carry out a parametric study to evaluate the effect of soil and pipe parameters on the soil resistance and the associated pullout forces. The results from these numerical simulations are then used to derive an expression that could be used to estimate an appropriate earth pressure coefficient that predicts the maximum axial soil resistance in these conditions. 


\section{Modeling buried structures subjected to soil movements}

The response of buried pipes to different modes of ground movements has been extensively investigated in the last few decades (e.g. [2, 7, 10, 18, 21, 25, 26, 37-39]. Roy et al. [33] used finite element (FE) analysis to model soil-pipe interaction in dense sand subjected to lateral ground displacements. Different soil models were evaluated and a parametric study was performed to examine the effect of both the pipe and soil properties on the response of the soil-pipe system. Zhang et al. [41] performed FE simulation to study the mechanical behavior of buried pipes crossing landslide zones. Despite the effectiveness of the FE analysis in studying this class of problems, modelling granular material and capturing particle movements during the pullout process is challenging using conventional continuum approaches [16].

As an alternative to continuum approaches, the discrete element method (DEM) has been used by researchers to model granular material under large deformation. The method was first proposed by Cundall and Strack [9] and was proven to be efficient in capturing the behavior of granular material. Tran et al. [35] developed a finite-discrete element framework for the 3D modeling of geogrid-soil interaction under pullout loading condition. The results demonstrated the capability of the coupled model to analyse this class of soil-structure interaction problems. In addition, Tran et al. [36] conducted discrete element analysis and experimental studies to determine the earth pressure distribution acting on cylindrical shafts experiencing large soil movement. Results confirmed the capability of the DEM in solving geotechnical engineering problems involving structural elements in moving granular materials. Ahmed et al. [1] investigated the distribution of earth pressures on buried pipes overlain by geogrid layer using finite-discrete element analysis. The results allowed for the evaluation of the effect of soil reinforcement on the radial earth pressure acting on the pipe. Rahman and Taniyama [31] conducted 3D discrete element analysis to calculate the response of a buried pipeline subjected to fault movement. Meidani et al. [24] evaluated the response of a buried steel pipe in granular soil to large ground movement using 3D discrete element analysis. Results confirmed the suitability of this numerical approach in solving soil-structure interaction problems under large deformation.

The above studies provided an insight into the response of buried structures to large soil movement using both finite and discrete element analysis. However, further investigations are needed to develop a better understanding of the role of different parameters on the response of rigid pipes to axial soil movement and propose an expression that could be used by practitioners to estimate the resistance of dense backfill material to pullout loading.

\section{Discrete element analysis}

The discrete element method generally considers the interaction between particles in a dynamic process. Following contact detection between two particles, the contact forces are calculated and the rotational and transitional accelerations are obtained using Newton's second law of motion. The accelerations are integrated numerically over a defined time step and particle velocities and new positions are determined. This process is continued until static equilibrium condition is reached. Energy dissipation during particle collision and interaction is considered using damping coefficients for both forces and moments. 
The discrete element analysis in this study is performed using the open source code YADE [23, 34]. The contact law between particles uses Cundall's linear elastic-plastic law with moment transmission. The microscopic parameters in this contact law involve elastic $\left(E_{\text {micro }}, K_{T} / K_{N}, \beta_{r}\right)$ as well as rupture parameters $\left(\phi_{\text {micro }}\right.$ and $\left.\eta_{r}\right)$. Where, $E_{m i-}$ cro is the particle modulus; $K_{N}$ and $K_{T}$ are the normal and tangential stiffnesses at the contact point; $\beta_{r}$ is the rolling resistance coefficient; $\phi_{\text {micro }}$ is the microscopic friction angle between particles, and $\eta_{r}$ is a dimensionless coefficient to define a threshold for the resistant moment. It should be noted that the modulus $\left(E_{\text {micro }}\right)$ and friction angle $\left(\phi_{\text {micro }}\right)$ are particle microscale parameters, which differ from the Young's modulus and friction angle of the soil domain. To keep the paper size manageable, the details of the contact model, damping equations, and other standard discrete element formulation that are available elsewhere $[12,20]$ are not presented.

\section{Effects of scale factor on discrete element results}

Accurate discrete element modeling of geotechnical problems requires the use of millions of particles. A discrete element sample cannot account for all discrete particles contained in the system and therefore "scaled-up" elements with larger sizes have to be used to reduce the size of the discrete element model to a reasonable level for the available computer resources. Several studies, including [8, 19, 22, 29, 30, 40, 42], demonstrated that the scale factor and model dimensions have significant effects on the discrete element simulation results, however, there is no universal agreement on a standard method to choose an appropriate scaling ratio for different applications.

Yang et al. [40] examined the factors affecting the strength and deformability of 2D discrete element models and concluded that the macroscopic properties are sensitive to $L / d$ ratio ( $L$ is the smallest length of the sample, $d$ is the median of the particle diameters used in the DE analysis), however, these properties tend to stabilize for $L / d$ ratio of more than 32. Furthermore, Ding et al. [13] created 3D models with $L / d$ ratios ranging from 10 to 50 for four different particle size distributions. It was found that both Young's modulus and Poisson's ratio do not significantly change for $L / d$ ratio of more than 25 . Based on the above, it is concluded that a minimum $L / d$ ratio of 30 should be used in this study to maintain the balance between the model scale and the accuracy of the calculated results.

\section{Description of the numerical model}

The results of the pullout experiments performed on a buried steel pipe in Fraser River Sand reported by Karimian [21] are used in this study to develop and calibrate the discrete element model. The dimensions of the soil container are $1.8 \mathrm{~m}$ in height, $2.5 \mathrm{~m}$ in width and $3.8 \mathrm{~m}$ in length. Graded Fraser River sand with a unit weight of $16 \mathrm{kN} /$ $\mathrm{m}^{3}\left(D_{r}=70 \%\right)$ and $d_{50}=0.22 \mathrm{~mm}$ was used as a backfill soil. The solid line in Fig. 1 represents the particle size distribution of this soil. The mechanical characteristics of the backfill material have been reported based on triaxial tests conducted under confining stress levels that vary from 15 to $50 \mathrm{kPa}$. Table 1 summarizes the sand properties used in the experiments. The steel pipe has an outside diameter of $46 \mathrm{~cm}$ and a wall thickness of $13 \mathrm{~mm}$ which represents a ring stiffness $\left(E I / \mathrm{r}^{3}\right)$ of $4.2 \mathrm{E} 6(\mathrm{kN} / \mathrm{m})$. This stiffness level prevents the generation of significant axial straining in the steel pipe during the 


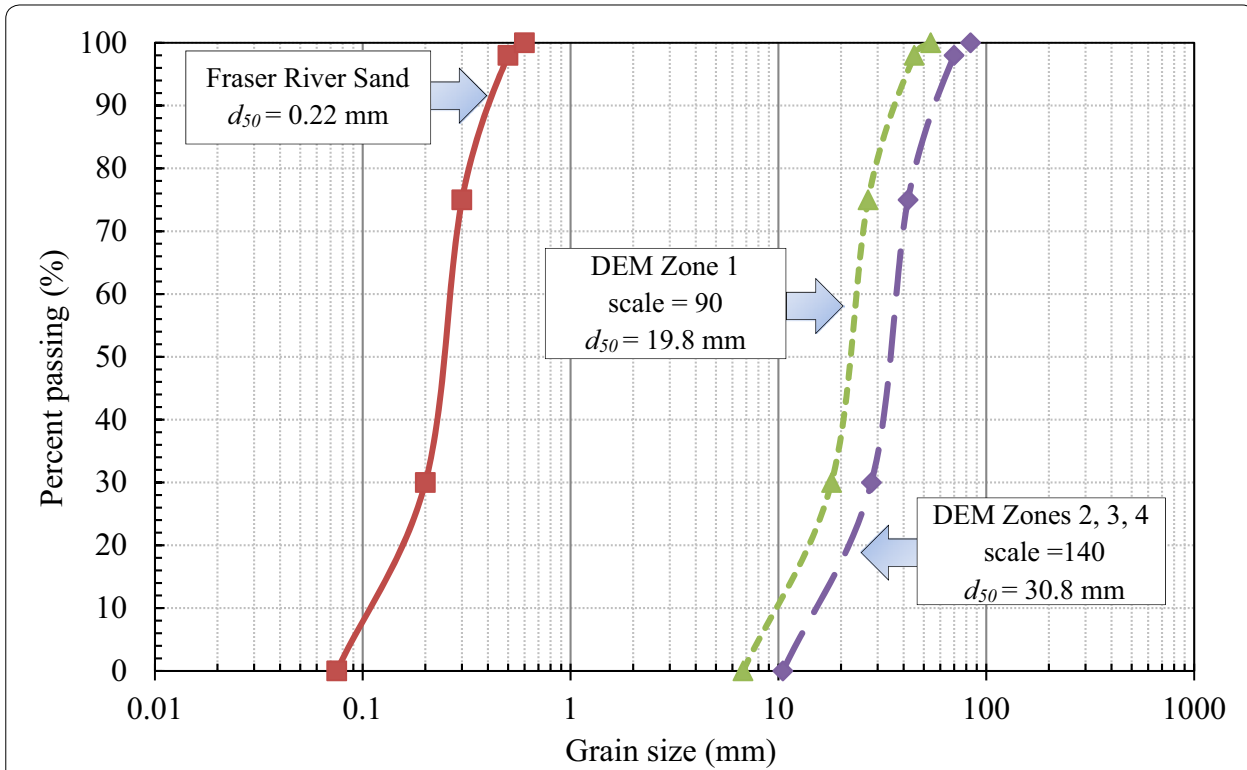

Fig. 1 Grain size distributions

Table 1 Soil properties of backfill material

\begin{tabular}{lc}
\hline Parameter & Value \\
\hline Specific gravity & 2.72 \\
Young's modulus, $E_{i}(\mathrm{MPa})$ & 40 \\
Unit weight $\left(\mathrm{kN} / \mathrm{m}^{3}\right)$ & 16 \\
Internal friction angle, $\phi$ (degree) & 45 \\
Cohesion $\left(\mathrm{kN} / \mathrm{m}^{2}\right)$ & 0 \\
Poisson ratio, $u$ & 0.3 \\
Porosity, $n$ & 0.41 \\
\hline
\end{tabular}

pullout. The interface friction angle $(\delta)$ between the pipe surface and the backfill material was reported to be $36^{\circ}$. The pipe was embedded in a $0.7 \mathrm{~m}$ layer up to the springline and covered with $1.15 \mathrm{~m}$ of backfill $(H / D=2.5)$. The pipe was pulled out at a fixed rate of $5 \mathrm{~mm} / \mathrm{s}$ and the pullout force was continuously measured.

\section{DEM specimen generation}

The discrete element model is created to reproduce the geometry and test procedure of the experiment. Up-scaled spherical particles are used to model the sand to reduce the number of particles and the required computation time. Based on the results of the scale-effect discussed above and considering a minimum $L / d$ ratio of 30 , particle scaling factors of 90 and 140 are chosen for the analysis and the generated samples follow the grain size distribution curves shown in Fig. 1. The DEM model used to simulate the experiment is divided into four zones (see Fig. 2). Zone 1 represents the area immediately around the pipe and contains smaller particles that have scale factor of 90 . This is important to improve the contact between the soil and the pipe. The outer Zones 2, 3 and 4 located away from the pipe contain larger size particles (scale factor of 140) as the 


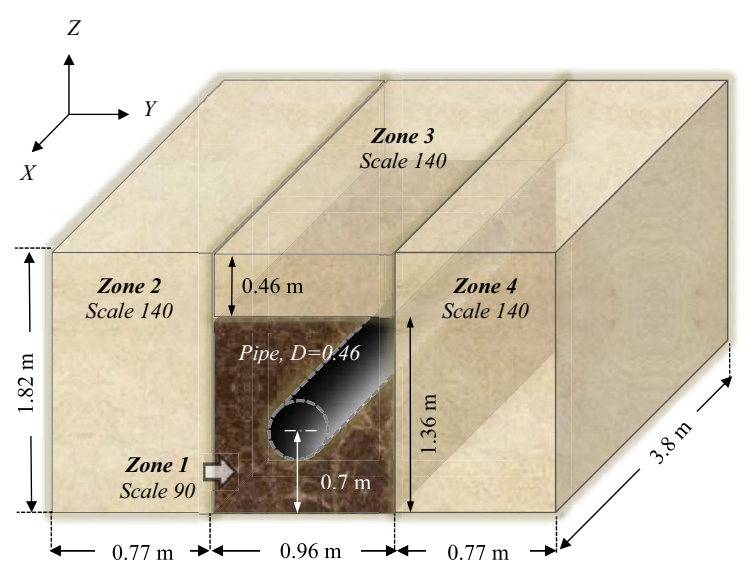

Fig. 2 Different particle size zones used to generate the discrete element model

stress gradients are expected to be much lower. Using these scale factors a total number of 265,000 spheres are generated to create the soil specimen. The fabric tensor of the sample was investigated following the approach proposed by Dang and Meguid [11]. It was found that the fabric tensor components are almost identical in all directions, which confirms that the discrete element sample is homogeneous.

The radius expansion packing method [20] is employed in this study to generate the discrete element particles. First, a box of non-contacting spheres is created in each zone following the particle size distribution given in Fig. 1. Particle radii are increased to match the porosity (0.41) of the backfill material. According to O'Sullivan [27], radius expansion method tends to generate specimens with isotropic stress state. To eliminate this effect, each zone is allowed to reach equilibrium independently. All four zones are then assembled together under gravity until equilibrium is re-established. A cut-out perspective of the created 3D model is presented in Fig. 3. The pipeline is modeled using 1216 facet discrete elements arranged in a hexdecagonal shape. Facets are triangular flat discrete particles that follow the same contact laws used of spherical particles. This means that facet-sphere collision is treated similar to sphere-sphere collision [34]. The length of the pipe is created that it is longer than the length of the chamber to allow for constant and continuous interactions between the pipe and soil during the pullout process. A close view of the pipeline and facet elements are presented in Fig. 3.

\section{Model calibration}

The input parameters for the discrete element analysis are determined by modeling triaxial tests and matching the results with the reported experimental data [21]. The triaxial specimen consists of a rectangular prism with an aspect ratio of two $(152 \mathrm{~mm}$ in height, $76 \mathrm{~mm}$ in length and width), which is consistent with the tested samples. The DEM specimen is created using the radius expansion method with grain size distribution similar to that of the backfill material. Considering the minimum length of the model $(76 \mathrm{~mm})$ and the median diameter of the particles, $L / d$ ratio of 30 is determined which is in good agreement with previous studies. A snapshot of the discrete element sample used in the triaxial test is given in Fig. 4a. 


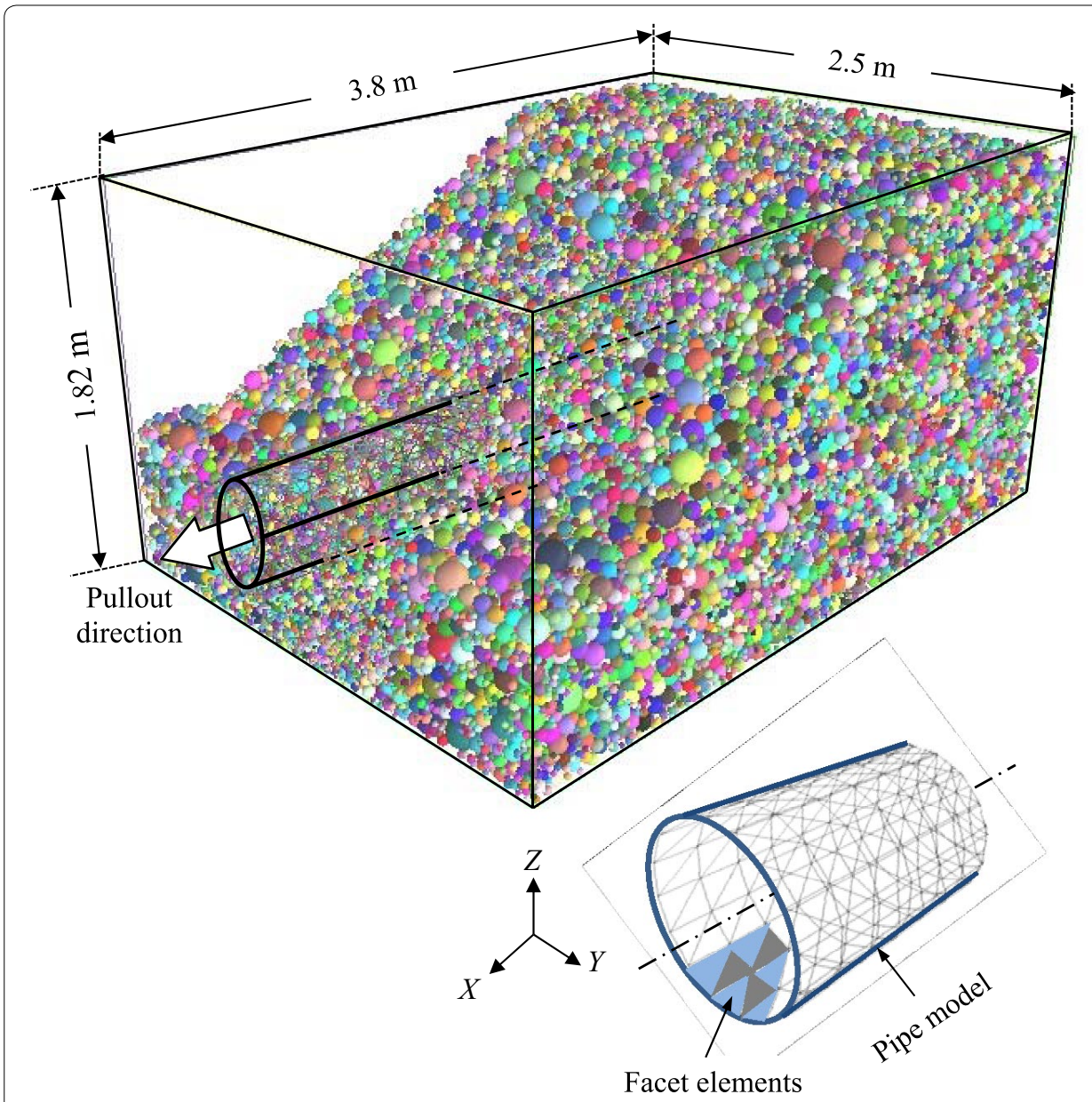

Fig. 3 Cut-out view of the model showing the pipeline and the surrounding soil

Three different confining stress levels are used in performing the triaxial tests, namely, 25, 35 and $50 \mathrm{kPa}$. First, the input parameters are obtained by matching the experimental results under a confining pressure of $25 \mathrm{kPa}$, following the calibration procedure proposed by Plassiard et al. [30]. Next, the parameters are validated using the triaxial test results with confining pressures of 35 and $50 \mathrm{kPa}$. The most important microscopic parameters are the particle modulus $\left(E_{\text {micro }}\right)$, the microscopic friction angle $\left(\phi_{\text {micro }}\right)$ and the rolling resistance $\left(\beta_{r}\right)$. Figure $4 \mathrm{~b}$ compares the numerically calculated and measured triaxial test results which shows an overall agreement for the used range of confining pressures, particularly near the peak values. It is also noted that the model underestimated the response by about $10 \%$ at small strains up to about $1.5 \%$ strain. This may be attributed to the simplified particle and model geometry used in the analysis. A summary of the soil input parameters are presented in Table 2.

\section{Modeling the pullout experiment}

Following the generation of the discrete particles in the predefined zones (see Fig. 2), the pipe is allowed to freely move under gravity before applying the pullout load. The accuracy of the created model is evaluated by calculating the radial earth pressure acting 
a

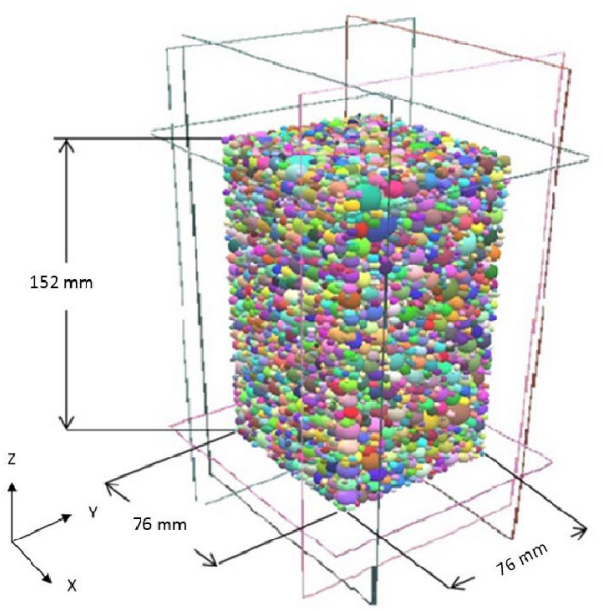

b

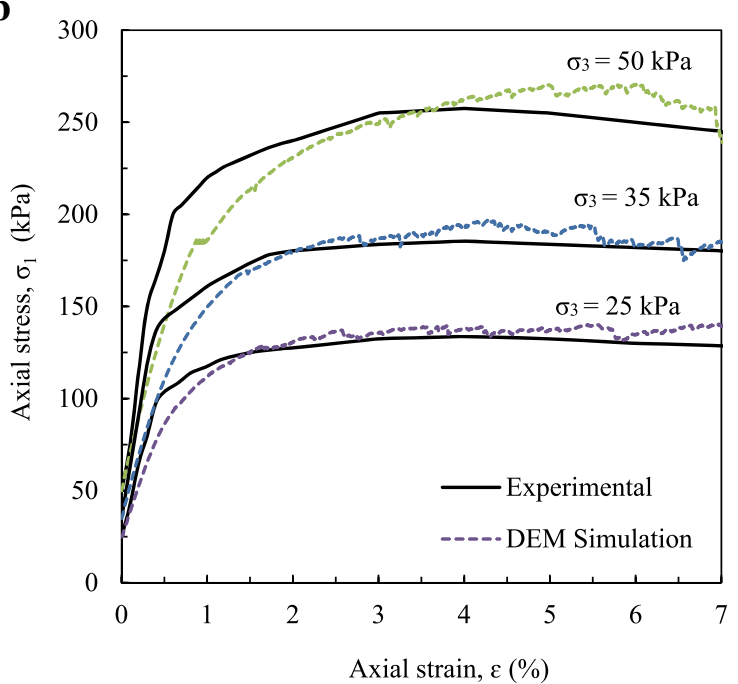

Fig. 4 Triaxial test used in calibration to find material input parameters: a tested sample; $\mathbf{b}$ results for different confining pressures

Table 2 Input parameters used in the numerical analysis

\begin{tabular}{ll}
\hline Parameter & Value \\
\hline Density $\left(\mathrm{kg} / \mathrm{m}^{3}\right)$ & 2720 \\
Particle modulus, $E(\mathrm{MPa})$ & 150 \\
$K_{T} / K_{N}$ ratio, $a$ & 0.7 \\
Micro friction angle, $\phi_{\text {micro }}$ (degree) & 35 \\
Rolling resistance coefficient $\left(\beta_{\mathrm{r}}\right)$ & 0.15 \\
$\eta_{\mathrm{r}}$ & 1 \\
Damping ratio & 0.2 \\
\hline
\end{tabular}

on the pipe and comparing the results with existing analytical solution [17]. The radial earth pressure on the pipe is calculated at five different locations (Invert, lower haunch, springline, upper haunch and crown) and then compared with the values obtained using 
Table 3 Comparison of calculated pressures with analytical solutions

\begin{tabular}{lll}
\hline Location & Initial earth pressure $\mathbf{( k P a )}$ & \\
\cline { 2 - 3 } & Hoeg's analytical solution & Discrete element analysis \\
\hline Crown & 17 & 15 \\
Upper haunch & 16 & 18 \\
Springline & 14 & 17 \\
Lower haunch & 16 & 15 \\
Invert & 17 & 17 \\
\hline
\end{tabular}

the numerical model. Table 3 summarizes the radial earth pressure values at these five locations. Although earth pressure was slightly overestimated near the springline, the overall distribution was consistent with the analytical solution. This demonstrates the effectiveness of the discrete element model in representing the interaction of the backfill material with the buried pipe. The difference in pressures at the springline and haunches is attributed to sensitivity of the contact pressures at these locations to the level of soil compaction around the pipe. Similar observations were made by Karimian [21] and Ahmed et al. [1].

The pullout test is simulated using a displacement control scheme with no friction between the box walls and the discrete particles, which is consistent with the boundary conditions used in the experiments. The pipe is pulled out in the analysis following the same displacement rate used in the experiment $(5 \mathrm{~mm} / \mathrm{s})$. Karimian [21] found that when the pullout rate ranges from 2 to $50 \mathrm{~mm} / \mathrm{s}$, the difference in peak axial force is negligible. Given the rate used in the analysis $(5 \mathrm{~mm} / \mathrm{s})$, the effect on the calculated pullout load is expected to be insignificant. The effect of the friction angle of the facet elements on the pullout force was evaluated using a parametric study [24]. Results indicated that the friction coefficient of the facet elements can affect the overall response of the model. Therefore, the friction angle needs to be determined accurately using experimental results. A friction angle of $30^{\circ}$ is found to bring the numerical results as close as possible to the experimental data. Figure 5 compares the measured and calculated axial soil resistance $\left(F_{A}\right)$ for a wide range of pipe displacements. The model seems to be able to accurately predict the axial resistance up to the peak value. Post peak, however, the model over-predicts the response by about $20 \%$. Since the focus of this study is on predicting the maximum axial soil resistance (pullout force), the performance of this simplified numerical model is judged to be adequate.

\section{Evaluating the effect of different parameters on the pullout force}

The axial soil resistance calculated using the closed-form solution (Eq. 1) is plotted in Fig. 5. It is clear that Eq. (1) significantly underestimates the pullout force. This difference is attributed to the increase in normal stresses acting on the pipe during the loading process, which is not accounted for in Eq. (1). The increase in normal stresses is generally explained by the dilatant behavior of the dense sand mobilized by the relative displacement between the sand material and the moving pipe [24]. Since $K_{0}$ parameter in Eq. (1) controls the average normal stresses on the pipe, a parametric study is performed using DEM to investigate the effect of different soil and pipe parameters on the pullout 


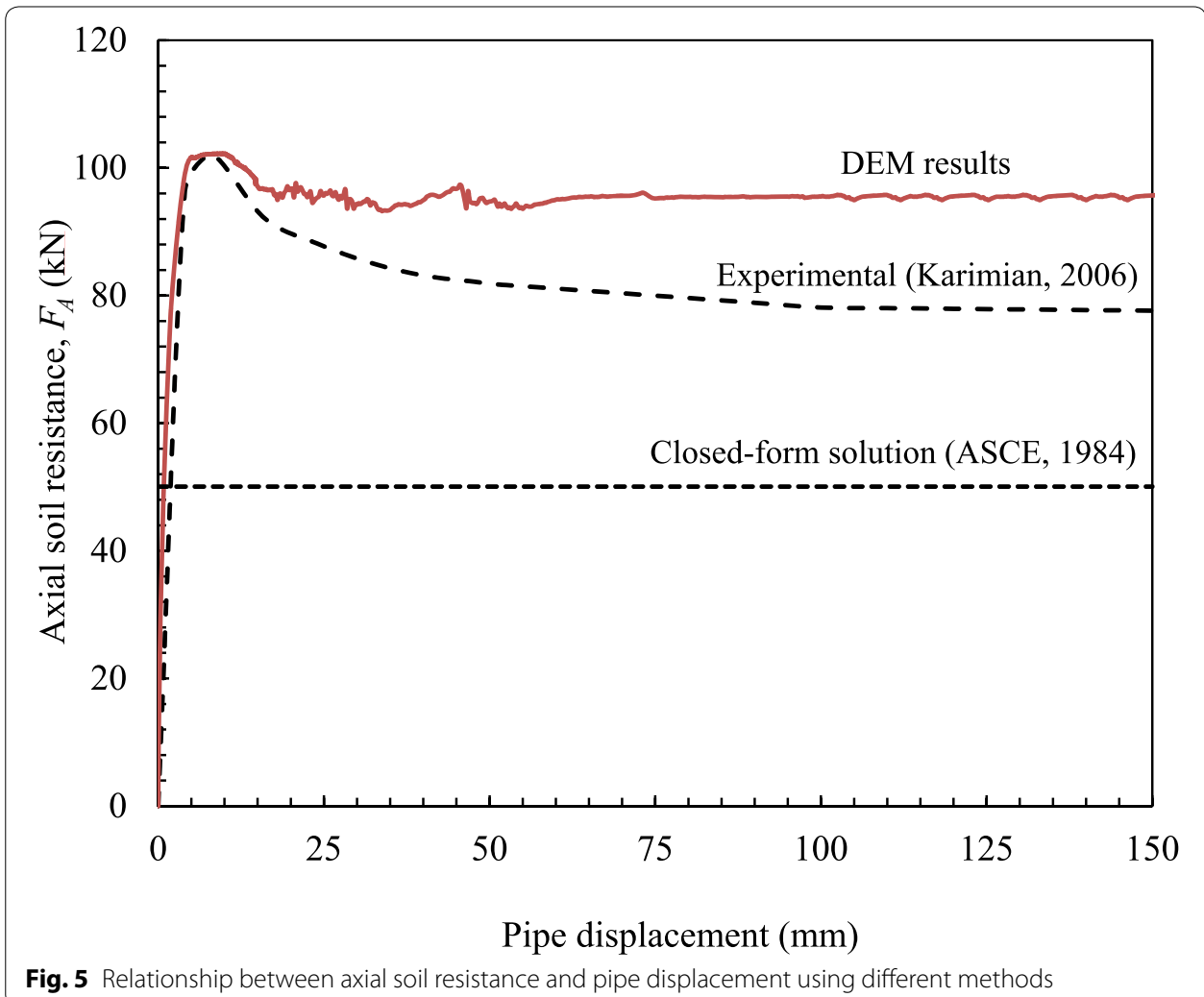

Table 4 Different soil and pipe parameters used in the parametric study

\begin{tabular}{ll}
\hline Parameter & Examined range of values \\
\hline Burial depth, $H(\mathrm{~m})$ & $1.1,1.35,1.6,1.85,2.1,2.35,2.6,2.85$ \\
Soil Young's modulus, $E(\mathrm{MPa})$ & $40,45,50,55$ \\
Soil friction angle, $\phi$ (degree) & $41,43,45,47$ \\
Interface friction angle, $\delta$ (degree) & $22.5,27,31.5,36,41,45$ \\
\hline
\end{tabular}

resistance and to propose a suitable expression for $K_{0}$ ( $K^{*}$ hereafter). The value of the modified earth pressure coefficient $K^{*}$ is bounded by $K_{0}$ and $K_{\mathrm{P}}$ (the passive earth pressure coefficient).

The investigated parameters include: (1) the burial depth $(H)$; (2) the soil friction angle $(\phi)$; (3) the soil Young's modulus $\left(E_{i}\right)$; (4) the pipe diameter $(D)$; and (5) the friction angle between the pipe and the soil $(\delta)$. The parametric study is performed by varying each parameter independently using the range of values given in Table 4. It should be noted that the soil modulus and friction angle in Table 4 are macro parameters. Simulations of triaxial tests were performed to determine the DEM micro parameters that correspond to the parameters listed in the table. The steps taken in developing the expression are listed below:

1. Substituting the numerically calculated pullout resistance for each case in Eq. (1), a value of $K^{*}$ is back-calculated.

2. A general relationship between $K^{*}$ and each of the examined parameters is established. 

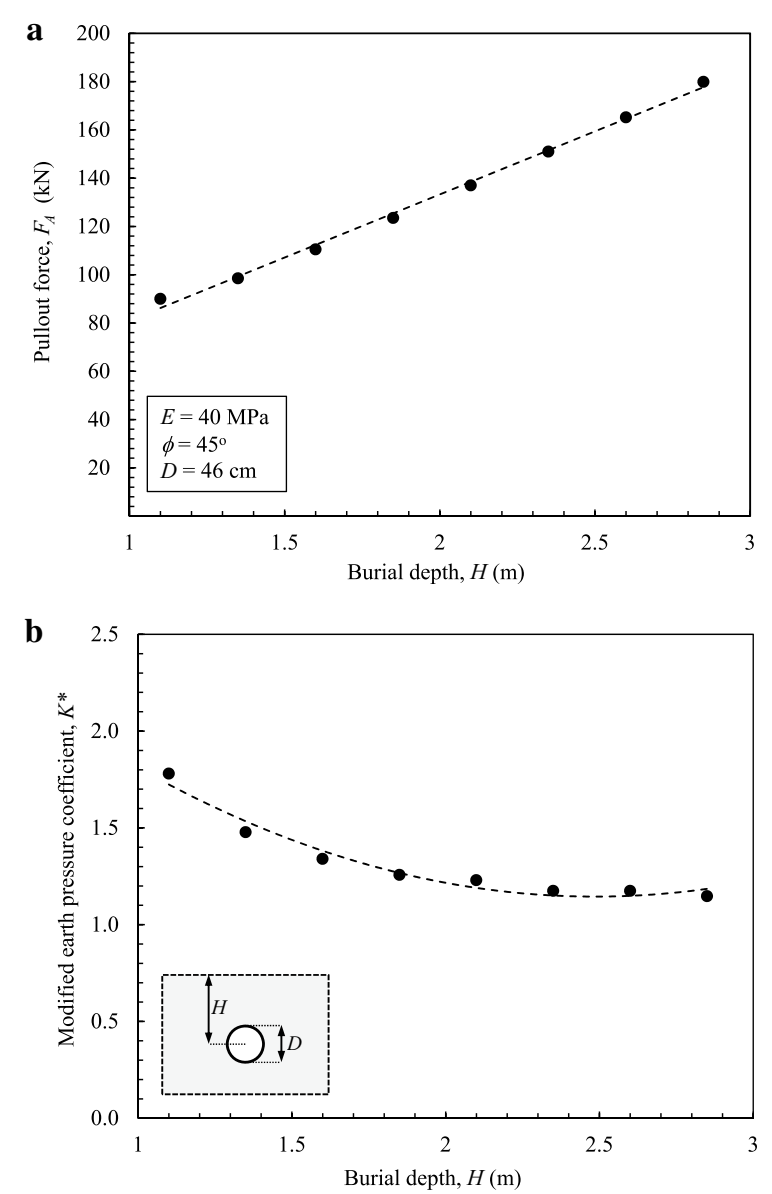

Fig. 6 Effect of burial depth on: a pullout force; $\mathbf{b}$ modified earth pressure coefficient

3. Combining all results and knowing the interaction of each parameter with $K^{*}$, a final expression is extracted using a multivariate regression analysis.

\section{Results and discussions}

\section{Effects of pipe burial depth $(H)$}

Burial depths are varied from 1.1 to $2.85 \mathrm{~m}$ which corresponds to overburden pressures that range from 17 to $46 \mathrm{kPa}$ at the springline. The soil and pipe properties summarized in Table 2 are used in the analysis keeping the pipe diameter constant at $46 \mathrm{~cm}$. As illustrated in Fig. 6a, the pullout load $\left(F_{A}\right)$ increases almost linearly with the increase in burial depth, which is consistent with the expected increase in radial pressure acting on the pipe.

Given the properties of both the soil and the pipe, the corresponding $K^{*}$ value is calculated using Eq. (1) and the results are presented in Fig. 6b. For the investigated properties, $K^{*}$ was found to decrease from 1.8 to 1.2 as the burial depth increased from 1.1 to $2.85 \mathrm{~m}$, respectively. No significant change in $K^{*}$ was found with further increase in burial depth. This is in agreement with the previously published results such as those reported by [21] and summarized in Table 5 . 
Table 5 Variation of $K$ with burial depth [21]

\begin{tabular}{llcc}
\hline & \multicolumn{2}{l}{ Dilation level (Expansion at pipe surface) in $\mathbf{~ m m}$} & $\mathbf{2}$ \\
\cline { 2 - 4 } & $\mathbf{1}$ & $\mathbf{1 . 5}$ & \\
\hline Burial depth $(\mathrm{m})$ & Calculated Kvalues & 2.6 & 2.8 \\
0.93 & 2.3 & 2.4 & 2.6 \\
1.86 & 2.2 & 2.3 & 2.4 \\
2.8 & 2.1 &
\end{tabular}

Effects of soil modulus $\left(E_{i}\right)$

Four different $E_{i}$ values were examined, namely, 40, 45, 50 and $55 \mathrm{MPa}$, which represent a range of values that are suitable for dense Fraser River sand material [21] under effective stress range between 15 and $50 \mathrm{kPa}$. Each of these values is used in the analysis along with three different burial depths, 1.6, 2.1 and $2.85 \mathrm{~m}$. Figure 7a shows the relationship between the pullout force $\left(F_{A}\right)$ and the soil modulus for the examined burial depths. Pullout force generally increased with the increase of burial depth. For a given value of $H$, the increase in Young's modulus resulted in a slight increase in the pullout force. Given the pipe diameter and backfill properties, $K^{*}$ is calculated for various soil moduli and the results are presented in Fig. $7 \mathrm{~b}$. The modified earth pressure coefficient, $K^{*}$ was found to decrease with the increase in burial depth. It was also found that the stiffer the soil (increasing elastic modulus), the higher the calculated $K *$ coefficient.

The above results indicate that the soil surrounding the pipe became stiffer as the radial pressure increased during the pullout process. This is consistent with the cylindrical cavity solution of [15]:

$$
\Delta \sigma_{n}=(4 G) / D \times \Delta t
$$

where $G$ is the soil shear modulus, $D$ is the pipe diameter and $\Delta t$ is the thickness of the shearing zone. This equation shows that the increase in normal stresses acting on the pipe due to soil dilation $\left(\Delta \sigma_{n}\right)$ is proportional to the shear stiffness of the soil $(G)$. Consequently, increasing the soil stiffness generally results in more pressure on the pipe.

\section{Effect of soil friction angle $(\phi)$}

In this part of the analysis, the Fraser River sand friction angle is increased in four increments $\left(41^{\circ}, 43^{\circ}, 45^{\circ}\right.$ and $\left.47^{\circ}\right)$ and its effect is evaluated for the investigated soil depths (1.6, 2.1 and $2.85 \mathrm{~m})$. Soil modulus and pipe diameter are kept constant at assigned values of $40 \mathrm{MPa}$ and $0.46 \mathrm{~m}$, respectively. The interface friction angle $(\delta)$ is adjusted to maintain the pipe roughness at a value of 0.8 of the soil friction angle throughout the analysis. As depicted in Fig. 8a, the pullout load slightly increased with the increase in soil friction angle for the three investigated burial depths. When the friction angle increased about $6^{\circ}$, the soil resistance (represented by $F_{A}$ value) increased about $17 \%$. Since the soil friction angle is directly related to the coefficient of earth pressure at rest $\left(K_{0}\right)$, the modified earth pressure coefficient $K^{*}$ is normalized in Fig. $8 \mathrm{~b}$ with respect to $K_{0}$. It is also found that for a given soil height, $K^{*} / K_{0}$ ratio increased with the increase in friction angle. In addition, increasing the burial depth resulted in a slight decrease in the earth pressure coefficient ratio as illustrated in Fig. 8b. 

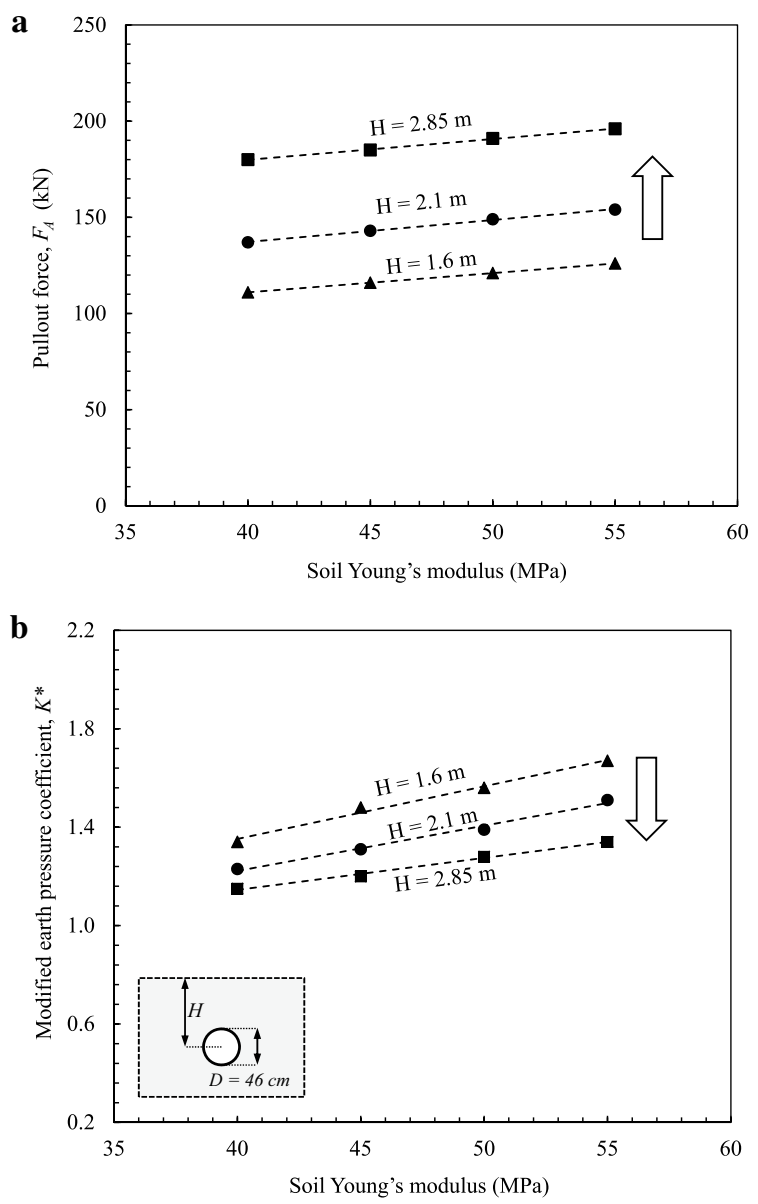

Fig. 7 Effect of soil modulus on: a pullout force; $\mathbf{b}$ modified earth pressure coefficient

\section{Effect of interface friction angle $(\delta)$}

Six different interface friction angles $\left(22.5^{\circ}, 27^{\circ}, 31.5^{\circ}, 36^{\circ}, 41^{\circ}\right.$ and $\left.45^{\circ}\right)$ are examined. These values represent $\delta / \phi$ ratios that range from 0.5 to 1 which are typical for sandsteel contacts [4]. To allow for the role of interface friction angle to be investigated, the rest of the variables including the pipe diameter, burial depth, particles friction angle and soil Young's modulus were kept constant. The results showed that the pullout force significantly increased as the interface friction angle increased as illustrated in Fig. 9a. It was also found that changing the interface had little effect on $K^{*}$ which remained constant for the investigated cases (Fig. 9b). This is in agreement with the observations made by [21] based on a sensitivity analysis of $K$ value with respect to the soil parameters (e.g. interface friction and dilation angles).

\section{Effect of pipe diameter $(D)$}

The effect of pipe diameter on the modified earth pressure coefficient $K^{*}$ is evaluated using the results reported by [21] for the same experiments investigated in this study. In addition to the pipe diameter used in the experiments $(46 \mathrm{~cm})$, two other diameters are examined, namely, 23 and $92 \mathrm{~cm}$. Burial depth was kept at $1.1 \mathrm{~m}$ with internal friction angle of $45^{\circ}$ and Young's modulus of $40 \mathrm{MPa}$. It should be noted that the wall thicknesses 

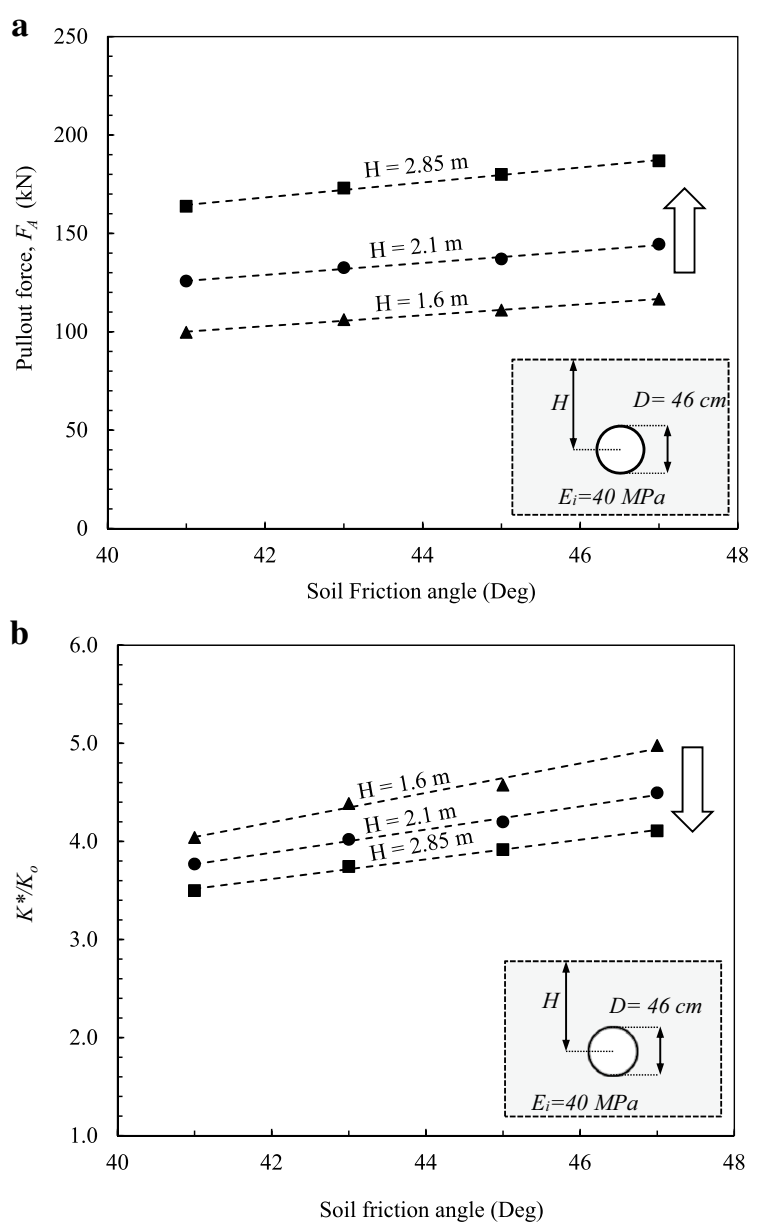

Fig. 8 Effect of friction angle a pullout force; $\mathbf{b}$ modified earth pressure coefficient

of the pipe were chosen to keep the rigidity of the pipe consistent in all investigated cases. The results presented in Fig. 10 showed that $K^{*}$ is inversely proportional to the pipe diameter. Since the normal pressure acting on the pipe due to soil dilation $\left(\Delta \sigma_{n}\right)$ is a function of $K^{*}$ (Eq. 2), it can be concluded that $\Delta \sigma_{n}$ is also inversely proportional to the pipe diameter.

\section{Development of an expression for $K^{*}$}

An expression for the maximum axial soil resistance against the movement of a steel pipe buried in dense sand is developed in this section based on the previous results. The proposed expression is a modification of Eq. (1) with $K^{*}$ replacing $K_{o}$. The modified earth pressure coefficient $K^{*}$ is a function of the burial depth $(H)$, soil modulus $\left(E_{i}\right)$, soil friction angle $(\phi)$ and pipe diameter $(D)$. The modified expression can be written as follows:

$$
F_{A}=0.5 \times \gamma^{\prime} \times H \times(\pi D L) \times(1+K *) \times \tan (\delta)
$$

$K^{*}$ is expressed by

$$
K^{*}=C \times K_{0} \times(E / \gamma H)^{\alpha} \times(\phi / 45)^{\beta} \times(\Delta t / D)^{\theta}
$$



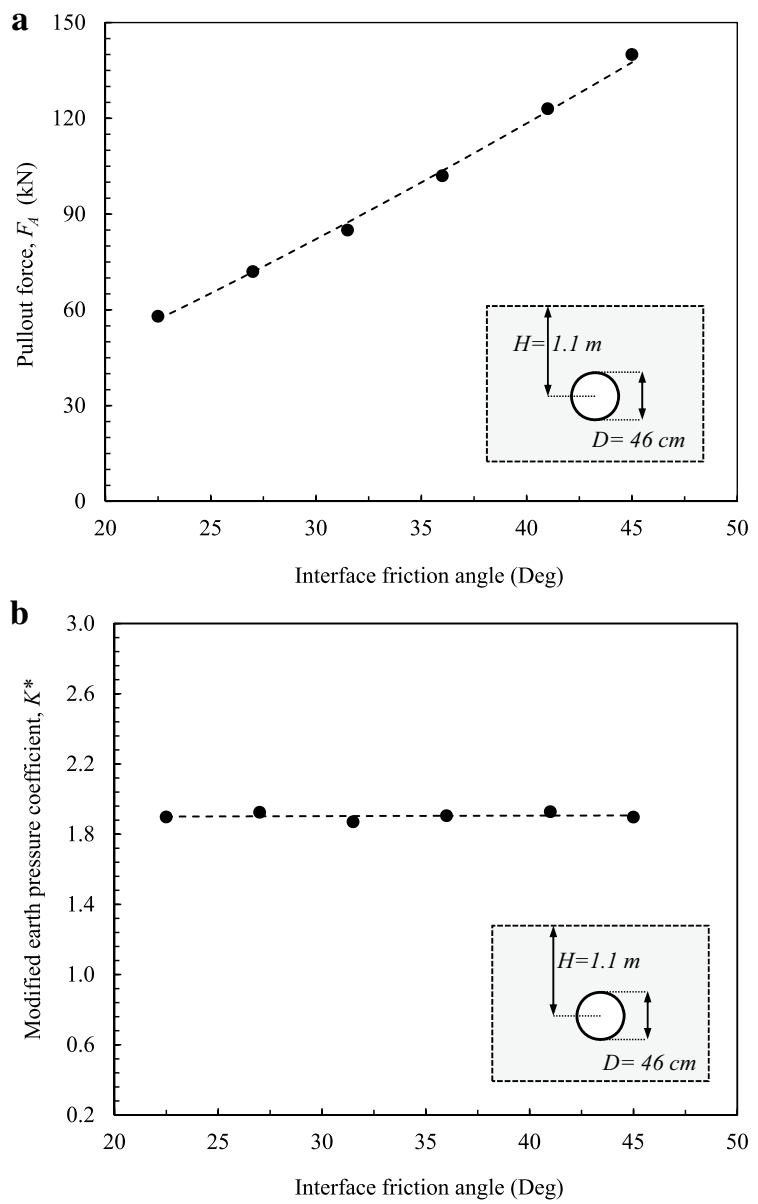

Fig. 9 Effect of interface friction angle $\mathbf{a}$ pullout force; $\mathbf{b}$ modified earth pressure coefficient

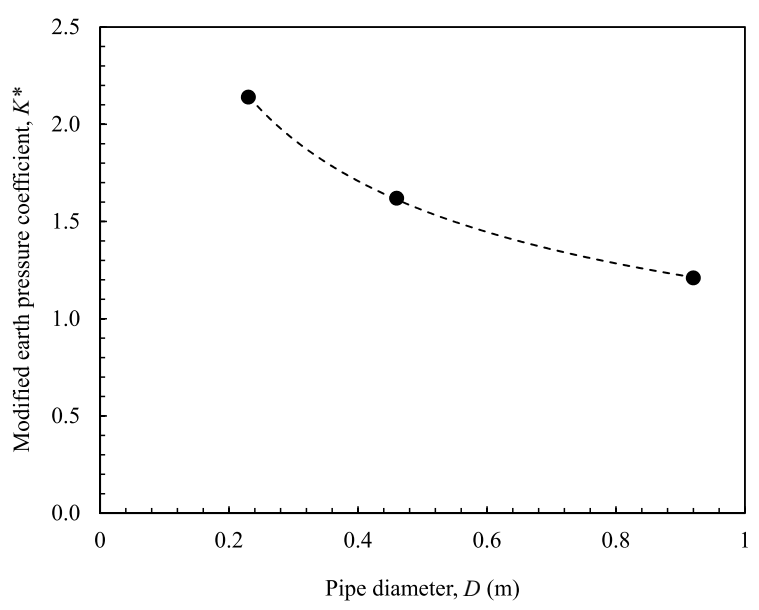

Fig. 10 Effect of pipe diameter on $K^{*}$

where $K^{*}$ is the modified coefficient of earth pressure, $C$ is constant, $K_{0}$ is the coefficient of earth pressure at rest, $E$ is the soil Young's modulus, $\gamma$ is the soil unit weight, $H$ is the pipe burial depth, $\phi$ is the soil friction angle, $\Delta t$ is the shear zone thickness and $D$ is the pipe diameter. 
Previous research related to shear zones developing in granular materials (e.g. [5, 32] revealed that the thickness of the active shear zone $(\Delta t)$ can be estimated as $10 d_{50}$ where $d_{50}$ is the median grain size of the soil. Karimian [21] observed that the thickness of the active shear zone surrounding the pipe is in the order of 1.2-2.8 mm. This is in agreement with $10 d_{50}$ for Fraser River sand $\left(d_{50}=0.22 \mathrm{~mm}\right)$ and consequently the thickness of the shear zone is set here to $2.2 \mathrm{~mm}$ in Eq. (4).

Using the data obtained from "Effects of pipe burial depth $(H)$ " through "Effect of interface friction angle $(\delta)$ " sections and utilizing multivariate regression analysis, the exponent $\alpha$ is calculated as 0.38 . This parameter accounts for the interaction between the soil stiffness and the vertical stresses at the springline of the pipe. The two other exponents, $\beta$ and $\theta$, are determined as 1.39 and 0.42 , respectively, and the constant $C$ is found to be 2.75 . The final expression can then be written as:

$$
K^{*}=2.75 \times K_{0} \times(E / \gamma H)^{0.38} \times(\varphi / 45)^{1.39} \times(\Delta t / D)^{0.42}
$$

\section{Validation of the proposed expression}

The validation was performed in two steps: (1) The changes in pullout force with the modified earth pressure coefficient were calculated numerically as well as using the proposed expressions; (2) a case study is presented where the pipe response measured during centrifuge experiments is compared with the pullout force calculated using the proposed method. This allows for the validity of the expression to be verified for different soil and pipe conditions. Finally a numerical example is provided to illustrate the use of the proposed approach.

Figure 11 compares the estimated values using equations (5) and (3) with the 3D numerical analysis. The results show a consistent agreement between the estimated and calculated values with a maximum difference of $6 \%$. Wijewickreme et al. [39] suggested that when using Eq. (1) to find the axial resistance in compacted sand, $K$ value should be considered within a range between $K_{0}$ and 2.5. The predicted $K^{*}$ values in this study (Fig. 11) are found to be within that range which shows the model prediction is also consistent with recommended practice.

A case study [10] that involves centrifuge tests and numerical analysis performed on a rigid pipe buried in dense sand and subjected to relative axial movement is used to further validate the proposed expression. The geometry and soil properties used in the experiments are provided in Fig. 12a. It was concluded that the ultimate axial soil resistance measured in the centrifuge tests was found to be higher than that predicted using Eq. (1).

Figure 12b compares the experimental results with the closed-form solution (Eq. 1) as well as the proposed expression. The vertical axis represents the axial interaction factor $\left(N_{t}\right)$ defined as:

$$
N_{t}=F_{A} / \gamma H D
$$

where $F_{A}$ is the ultimate axial force per unit length.

The value of the normalized $N_{t}$ factor is determined based on the centrifuge test results for a steel pipe $504 \mathrm{~mm}$ in diameter buried to a depth of $1 \mathrm{~m}$ in sandy soil 


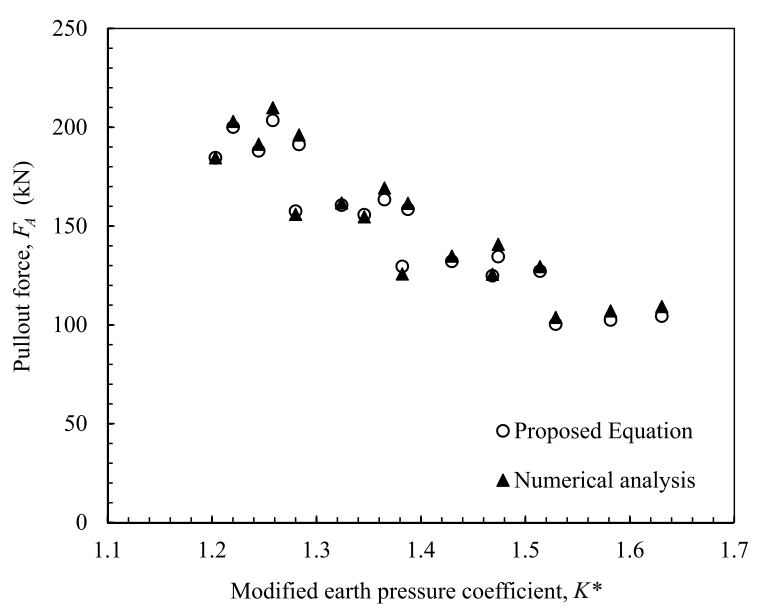

Fig. 11 Calculated pullout force using the proposed expression

(density $=6 \mathrm{kN} / \mathrm{m}^{3}, \mathrm{D}_{\mathrm{r}}=0.82$, friction angle of $43^{\circ}$ ) and is found to be about 2.1. The closed-form solution (Eq. 1) calculated $N_{t}$ value of about 0.38 whereas the proposed expression predicted $N_{t}$ value of 1.95 as shown in Fig. 12b.

Example To illustrate the use of the proposed expression (Eq. 5) to estimate the pullout resistance of a typical steel pipe, a numerical example is given below.

Consider a steel pipe that has a diameter $(D)$ of $0.5 \mathrm{~m}$ buried at a depth $(H)$ of $1.5 \mathrm{~m}$ in dense sand with friction angle $(\phi)$ of $38^{\circ}, d_{50}=0.2 \mathrm{~mm}$, Young's modulus $(E)$ of $45 \mathrm{MPa}$, unit weight of $17 \mathrm{kN} / \mathrm{m}^{3}$ and interface friction angle $(\delta)$ of $30^{\circ}$. Based on the classical ASCE equation, the maximum axial soil resistance $\left(F_{A}\right)$ obtained using Eq. (1) is about $16 \mathrm{kN} / \mathrm{m}$.

Using the proposed expression, the corrected $K^{*}$ value can be estimated as follows:

$$
\begin{aligned}
& (E / \gamma H)^{0.38}=\left(4.5 \mathrm{e} 4 \mathrm{kPa} /\left(17 \mathrm{kN} / \mathrm{m}^{3} \times 1.5 \mathrm{~m}\right)^{0.38}=17.13\right. \\
& (\varphi / 45)^{1.39}=\left(38^{\circ} / 45^{\circ}\right)^{1.39}=0.791 \\
& (\Delta t / D)^{0.42}=((10 \times 0.0002) \mathrm{m} / 0.5 \mathrm{~m})^{0.42}=0.0984 \\
& K^{*}=2.75 \times(1-\sin (38)) \times 17.13 \times 0.791 \times 0.0984=1.41
\end{aligned}
$$

Knowing $K^{*}$ and using Eq. (3), the maximum axial soil resistance $\left(F_{A}\right)$ is estimated as $28 \mathrm{kN} / \mathrm{m}$.

\section{Limitations}

Despite the ability of the proposed expression to reasonably estimate the earth pressure coefficient for steel pipes subjected to axial soil movement, further research is needed to develop a more comprehensive relationship that is applicable to other buried pipes and backfill material. The focus of this study was directed towards steel pipes buried in 

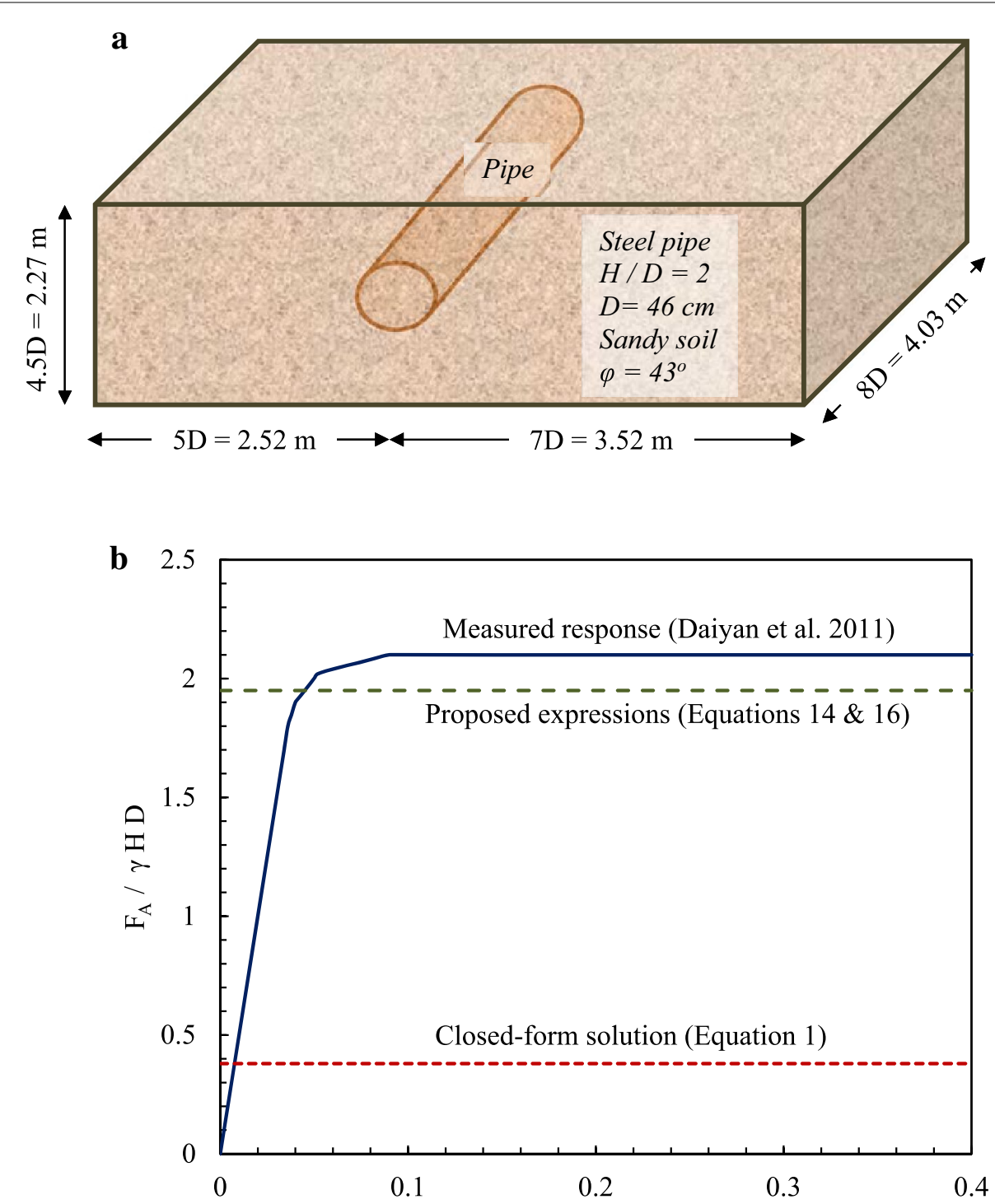

Pipe axial displacement / Pipe diameter

Fig. 12 Case study a Problem geometry, b comparison between calculated and measured axial interaction factor

dense sand under static pullout loading condition. Changing the sand type may affect the thickness of the shear zone around the pipe and, therefore, the results may deviate from the proposed expression and the reported experimental data. In addition, the proposed approach may not be applicable for flexible pipes (e.g. thin-walled polyethylene) as they are relatively extensible and may experience changes in cross-sectional dimension under axial loading condition.

Although using simplified spherical elements in this study was justified by the problem size and the associated computational cost, using non-spherical elements (clumps) may improve the numerical predictions. However, this was not considered in the present study. 


\section{Summary and conclusions}

To evaluate the effect of ground movement on existing pipelines, it is sometimes necessary to estimate the maximum soil resistance to axial loading. Although the available closed form solution [4] can provide a reasonable estimate of the axial soil resistance for loose backfill, it significantly underestimates the resistance for dense sand material. In this study, a series of 3D discrete element analyses is performed to investigate the response of a steel pipe buried in dense sand subjected to axial soil movement. Model validation is performed by comparing the calculated pullout resistance with experimental data. Pullout forces developing in dense sand material are found to be significantly higher as compared to the values obtained using closed-form solution. Based on the results of this study, a modified expression is proposed to estimate a modified earth pressure coefficient that is appropriate for dense sand condition.

The proposed expression for the modified earth pressure coefficient $(K *)$ is found to be function of the soil and pipe properties, including pipe diameter and burial depth, soil modulus, and particle friction angle. For a given soil and pipe parameters, the pullout response predicted using the proposed expression is found to be in agreement with that measured in the experiments and calculated using numerical analysis.

This paper suggests that for a steel pipe buried in dilative soils, using the available closed-form solution may significantly underestimates the axial soil resistance. It is noted that the proposed expression is suitable only for steel pipes buried in dense sand material. More experimental studies are needed to confirm the applicability of the expression to other types of dilative soils.

Authors' contributions

MM carried out this numerical study under the guidance of both MAM and LEC. All authors read and approved the final manuscript.

Acknowledgements

This research is supported by the Natural Sciences and Engineering Research Council of Canada (NSERC). Financial support provided by McGill Engineering Doctoral Award (MEDA) to the first author is appreciated.

Competing interests

The authors declare that they have no competing interests.

Ethics approval and consent to participate

Not applicable.

\section{Publisher's Note}

Springer Nature remains neutral with regard to jurisdictional claims in published maps and institutional affiliations.

Received: 3 December 2017 Accepted: 27 March 2018

Published online: 12 April 2018

\section{References}

1. Ahmed MR, Tran VDH, Meguid MA (2015) On the role of geogrid reinforcement in reducing earth pressure on buried pipes: experimental and numerical investigations. Soils Found 55(3):588-599

2. Almahakeri M, Moore ID, Fam A (2016) Numerical study of longitudinal bending in buried GFRP pipes subjected to lateral earth movements. J Pipeline Syst Eng Pract 12:04016012

3. American Lifeline Alliance-ASCE (2001) Guideline for the design of buried steel pipe. ASCE Press, New York. https:// www.americanlifelinealliance.org/Product_new3.htm. Accessed 15 nov 2017

4. ASCE (1984) Guidelines for the seismic design of oil and gas pipeline systems. Committee on gas and liquid fuel lifelines. American Society for Civil Engineering (ASCE), New York

5. Bridgewater J (1980) On the width of failure zones. Geotechnique 30(4):533-536

6. Canadian Energy Pipeline Association (CEPA). http://www.cepa.com/. Accessed 1 Dec 2017 
7. Chan PDS, Wong RCK (2004) Performance evaluation of a buried steel pipe in a moving slope: a case study. Can Geotech J 41(5):894-907

8. Cho N, Martin C, Sego D (2007) A clumped particle model for rock. Int J Rock Mech Min Sci 44(7):997-1010

9. Cundall PA, Strack OD (1979) A discrete numerical model for granular assemblies. Geotechnique 29(1):47-65

10. Daiyan N, Kenny S, Phillips R, Popescu R (2011) Investigating pipeline-soil interaction under axial-lateral relative movements in the sand. Can Geotech J 48(11):1683-1695

11. Dang HK, Meguid MA (2010) Algorithm to generate a discrete element specimen with predefined properties. Int J Geomech 10(2):85-91

12. Dang HK, Meguid MA (2013) An efficient finite-discrete element method for quasi-static nonlinear soil-structure interaction problems. Int J Numer Anal Methods Geomech 37(2):130-149

13. Ding $X$, Zhang L, Zhu H, Zhang Q (2014) Effect of model scale and particle size distribution on PFC3D simulation results. Rock Mech Rock Eng 47:2139-2156

14. European Gas Pipeline Incident Data Group (2015) Gas pipeline incidents. European Gas pipeline Incident Data Group (EGIG), Groningen, Netherlands. 9th EGIG Report 1970-2015, No. EGIG 05-R-0002

15. Gibson RE, Anderson WF (1961) In situ measurement of soil properties with the pressuremeter. Civil Eng Public Works Rev 56(658):615-618

16. Guo PJ, Stolle DFE (2005) Lateral pipe-soil interaction in sand with reference to scale effect. J Geotech Geoenviron Eng ASCE 131(3):338-349

17. Hoeg K (1968) Stresses against underground structural cylinders. J Soil Mech Found 94(4):833-858

18. Honegger DG, Nyman DJ (2004) Guidelines for the seismic design and assessment of natural gas and liquid hydrocarbon pipelines. Pipeline Research Council International Inc., Arlington

19. Huang H (1999) Discrete element modeling of tool-rock interaction. Ph.D. thesis, University of Minnesota, Minneapolis

20. Itasca (2004) PFC 2D 3.10 particle flow code in two dimensions, theory and background, 3rd edn. Minneapolis, USA

21. Karimian H (2006) Response of buried steel pipelines subjected to longitudinal and transverse ground movement. Ph.D. thesis, Department of Civil Engineering, The University of British Columbia, Vancouver

22. Koyama T, Jing L (2007) Effects of model scale and particle size on micro-mechanical properties and failure processes of rocks - a particle mechanics approach. Eng Anal Boundary Elem 31(5):458-472

23. Kozicki J, Donzé VF (2008) A new open-source software developed for numerical simulations using discrete modeling methods. Comput Methods Appl Mech Eng 197:49-50

24. Meidani M, Meguid MA, Chouinard LE (2017) Evaluation of soil-pipe interaction under relative axial ground movement. J Pipeline Syst Eng Pract 4:4017009

25. Newmark M, Hall WJ (1975) Pipeline design to resist large fault displacement. In: Proceedings of the US national conference on earthquake engineering, Ann Arbor, Mich. Earthquake Engineering Research Institute, Oakland, California. Paper No. UILU-ENG-75, pp 416-425

26. O'Rourke MJ, Nordberg C (1992) Longitudinal permanent ground deformation effects on buried continuous pipelines, Technical report NCEER-92-0014. Natl Center Earthquake Eng Res, Buffalo

27. O'Sullivan C (2011) Particulate discrete element modeling, a geomechanics perspective. Spon Press, London

28. Paulin MJ, Phillips R, Clark JI, Trigg A, Konuk I (1998) A full-scale investigation into pipeline/soil interaction. In: Proceeding of the international pipeline conference, Calgary; June 1988

29. Potyondy DO, Cundall PA (2004) A bonded-particle model for rock. Int J Rock Mech Mining Sci 41 (8):1329-1364

30. Plassiard JP, Belheine N, DonzâE FV (2009) A spherical discrete element model: calibration procedure and incremental response. Granular Matter 11:293-306

31. Rahman MA, Taniyama H (2015) Analysis of a buried pipeline subjected to fault displacement: a DEM and FEM study. Soil Dyn Earthquake Eng 71(1):49-62

32. Roscoe KH (1970) 10th Rankine lecture: the influence of strains in soil mechanics. Geotechnique 20(2):129-170

33. Roy K, Hawlader B, Kenny S, Moore I (2016) Finite element modeling of lateral pipeline-soil interactions in dense sand. Can Geotech J 53(3):490-504

34. Smilauer V et al (2010) Yade documentation. The Yade project 2010. http://yade-dem.org/doc (28 October 2013). Accessed 1 Dec 2017

35. Tran VDH, Meguid MA, Chouinard LE (2013) A finite-discrete element framework for the 3D modeling of geogridsoil interaction under pullout loading conditions. Geotext Geomembr 37:1-9

36. Tran VDH, Meguid MA, Chouinard LE (2014) Discrete element and experimental investigations of the earth pressure distribution on cylindrical shafts. Int J Geomech 14(1):80-91

37. Trautmann CH, O'Rourke TD (1983) Behavior of pipe with dry sand under lateral and uplift loading, geotechnical engineering report 83-7. Cornell University, Ithaca

38. Weerasekara Lalinda, Wijewickreme Dharma (2008) Mobilization of soil loads on buried, polyethylene natural gas pipelines subject to relative axial displacements. Can Geotech J 45:1237-1249

39. Wijewickreme D, Karimian H, Honegger D (2009) Response of buried steel pipelines subjected to relative axial soil movement. Can Geotech J 46(7):735-752

40. Yang B, Jiao Y, Lei $S$ (2006) A study on the effects of microparameters on macroproperties for specimens created by bonded particles. Eng Comput 23(6):607-631

41. Zhang Jie, Liang Zheng, Han Chuanjun (2016) Mechanical behavior analysis of the buried steel pipeline crossing landslide area. J Press Vessel Technol 138(5):051702

42. Zhang X-P, Wong L (2012) Cracking processes in rock-like material containing a single flaw under uniaxial compression: a numerical study based on parallel bonded-particle model approach. Rock Mech Rock Eng 45(5):711-737 